\title{
Toxic Effects of Organophosphates Pesticides. A Review
}

\author{
Ayobami A. L. ${ }^{1 *}$, Kade E. A. ${ }^{\text {, Oladimeji K. A. }}{ }^{2}$, Kehinde S. ${ }^{3}$ and Gurpreet K. ${ }^{4}$ \\ 1 Department of Microbiology, University of Lagos (UNILAG), Akoka, Lagos, Nigeria. \\ 2 National University of Ireland Galway, Ireland and University of Limerick \\ 3 Department of Cell biology and Genetics, University of Lagos (UNILAG), Akoka, Lagos, Nigeria; \\ 4 Department of Health and Health Care Administration, Swami Rama Himalayan University (SRHU), \\ Dehradun, Indian \\ * Correspondence: ayobamiadesiyan123@gmail.com; ORCID: 0000-0001-8240-5754
}

\begin{abstract}
Organophosphate pesticides (also known OPPs) have for many years been the choice candidate globally for pest control. OPPs have for over 80 years, been used in gardens, fields and greenhouses as crop protection agents, and even in homes as insecticides and mosquito abatement. Thus, year after year and with the repeated application of organophosphate agents, many problems have appeared as a result of excessive use of pesticides. The adverse effects of pesticides are well documented in human health, environment, pesticide residue in crops, soil and water contaminated by these pesticides. Therefore, it is necessary to shed more light on the risks associated with the irresponsible usage of organophosphate pesticides.
\end{abstract}

Keywords: organophosphate pesticides; pesticide toxicology; human health; environment

\section{Introduction}

Organophosphates pesticides (OPPs) form the large groups of chemicals being used over the past 80 years for protecting crops, livestock, human health from pests and as warfare agents. Organophosphates (OPs) are chemical substances originally produced by the reaction of alcohols and phosphoric acid (1). On the basis of structural characteristics they are divided into 13 types or more such as phosphates, phosphonates, phosphinates, phosphorothioates, phosphonothioates, phosphorodithioates, phosphorotrithioates, phosphoramidothioates (6).

OPPs are the most widely used insecticide worldwide and their metabolites are widespread across different populations (4). Organophosphates effect on insects and mammals is primarily by phosphorylation of the acetylcholinesterase enzyme (AChE) at nerve endings. Therefore, a loss in available AChE occurs and the affected organ becomes over-stimulated by the excess acetylcholine (ACh, the impulse-transmitting substance) in the nerve endings. Some critical proportion of the tissue enzyme mass must be inactivated by phosphorylation before symptoms and signs of poisoning become manifest. At sufficient dosage, loss of enzyme function allows accumulation of ACh peripherally at cholinergic neuroeffector junctions (muscarinic effects), skeletal nerve-muscle junctions, and autonomic ganglia (nicotinic effects), as well as centrally (Routt and Roberts, 1999). It has been observed that absorption of Organophosphates through skin and gut wall is greatly increased by fat solvents. These compounds are volatile and their significant part is stored in fat tissue and is excreted through biliary and urinary pathways, while storable lipophilic compounds could be excreted from maternal milk (2).They affect central nervous system causing hyper-excitable state in brain, convulsions, tremor, hyper-reflexia and ataxia (3).

It has been widely reported and documented in various publications in the last 35 years that Pesticides especially Organophosphates group are responsible for admission of millions of people to hospitals with accidental poisoning, in addition to suicidal cases. Meanwhile, it was estimated that about 25 million agricultural workers suffer from poisoning every year in the third world countries (3). Thus, this work aimed to make a small reminder about the risks of organophosphate pesticides. 


\section{The Impacts of Organophosphate Pesticides on Human Health}

Different authors have proved OPPs to be hazardous to humans by using different tests [7]. Guptal et al. [8] presented data on pesticide residues in milk from Indonesian women which demonstrated general exposure to OPPs. Similarly, other studies [9-10] have also demonstrated the presence of phosphate in human milk. The use of titanium dioxide nanoparticles (nano-TiO2) for the degradation of Organophosphates increases the risk of exposure to trace nano-TiO2 and OPPs mixtures. The interaction of Organophosphates and nano $\mathrm{TiO} 2$ at low concentrations may alter toxic response relative to nano-TiO2 alone. Addition of trace nano-TiO2 with OPPs synergistically enhanced genotoxicity via increasing oxidative stress, oxidative DNA adducts, DNA breaks, and chromosomal damage in human embryo L-02 hepatocytes.

Body organs like brain, liver, kidneys, ovaries etc., were affected by organophosphates poisons causing structural and chemical changes, as well as growth retardation. In a study carried out for two years with dogs, results showed that $7.5 \mathrm{mg}$ kg-1 day- 1 atrazine dose caused reduction in food intake and increased heart and liver weights. The NOEL on rat was $70 \mathrm{mg} \mathrm{kg}-1$ whereas in dog it was $15 \mathrm{mg}$ kg-1 of body weight (12).

\section{Mutagenic and Carcinogenic Effects}

Many Organophosphorus pesticides have not shown carcinogenic potential in animal experiments, but some pesticides do, through induction of tumors in rats and mice. No generalizations can be made due to some compounds exhibiting mutagenic activity, whereas other compounds do not (13).

Daily application of technical (85\%) diazinon $(20$ or $40 \mathrm{mg} / \mathrm{kg}$ body weight) to the skin of Dark Agouti rats just above the tail produced a 4-fold increase in faecal porphyrins, after 8 - 12 weeks. However, they also found that Isodiazinon was very effective in causing porphyrin accumulation, when added to cultures of chick hepatocytes (13-14)

Detailed data on the effects of organophosphate occupational exposure on pregnant women and their fetuses are not available, although such information would be valuable. In humans, only a few cases of acute organophosphorus insecticide poisoning during pregnancy have been described. A 24year-old woman in her third month of pregnancy injected herself with Malathion in a suicide attempt. A therapeutic abortion was performed 2 months later. Continuation of the pregnancy was considered to be dangerous, although the condition of the fetus was not described (14).

\section{Toxicological Studies among Rats}

Acute toxicity is the ability of a substance to cause harmful impacts soon after a single exposure or dose or any severe poisonous effect resulting from a single short-term exposure to a toxic substance. LD50 (lethal dose 50) is defined as the dose that kills 50\% of a population of the tested animals (6-7), Profenofos is an insecticide, miticide and acaricide used only on cotton. In an acute study, neurotoxic signs were seen at $190 \mathrm{mg} / \mathrm{kg}$ in rats, and were more prominent in females. Also, in vitro studies have shown butyl cholinesterase to be more sensitive to profenofos inhibition than acetyl cholinesterase (AChE) (10).

\section{Reproductive and Cytogenetic Effects}

A number of pesticides clearly have the potential to cause reproductive toxicity in animals, and many compounds e.g. (chlordecone ) are known to affect human reproduction (12). Also, OPPs including insecticides (malathion, parathion, diazinon, fenthion, dichlorvos, chlorpyrifos, ethion), nerve gases (soman, sarin, tabun, VX), ophthalmic agents (echothiophate, isoflurophate), and antihelmintics (trichlorfon). Herbicides (tribufos [DEF], merphos) are tricresyl phosphate containing industrial chemicals. Cytogenetic damage related to pesticides exposure has been reported in various populations. Some investigators have reported significant differences in the percentage of 
chromosomal aberrations (CAs) in exposed individuals (range, 2.66-10.30\%) compared with control (range, $0.53-5.52 \%)(12)$.

\section{Effects on the Immune System}

The most Organophosphorus pesticides elicit autoimmune reactions and suppress the production of antibodies against vaccines (13). Studies showed that pesticide exposure significantly reduces resistance to bacterial, viral, and parasitic infections and promotes tumor growth in many animal species. People exposed to pesticides are at increased risk of contracting certain cancers known to be associated with immune suppression. In summary, pesticides could cause a variety of cancers through an immunological mechanism (12).

There are scientific evidences suggesting that many pesticides damage the immune system. Animal studies have shown that pesticides alter the immune system's normal structure, disturb immune responses, and reduce animal's resistance to antigens and infectious agents. In the case of Malathion which is considered a very low toxic compound (oral LD50 $=2100 \mathrm{mg} / \mathrm{kg} \mathrm{bw}$ ), for example, deregulates the immune system, especially affecting non-specific immune mechanisms (12-13).

\section{References:}

[1] Mohamed A. Ghorab, Mohamed S. Khalil. Toxicological Effects of Organophosphates Pesticides. International Journal of Environmental Monitoring and Analysis. Vol. 3, No. 4, 2015, pp. 218-220. doi: 10.11648/j.ijema.20150304.13

[2] Alavanja, M. C. (2009). Introduction: pesticides use and exposure extensive worldwide. Rev Environ Health. 24(4):303-309.

[3] Aprea, C.; Strambi, M.; Novelli, M.T.; Lunghini, L. and Bozzi, N. (2000). Biologic monitoring of exposure to organophosphorus pesticides in 195 Italian children. Environ Health Perspect. 108 (6): 521-5. [4] Barr, D.B.; Bravo, R.; Weerasekera, G.; Caltabiano, L.M.; Whitehead, R.D. J.; Olsson, A.O.; Caudill, S.P.; Schober, S.E.; Pirkle, J.L. and Sampson, E.J. (2004). Concentrations of dialkyl phosphate metabolites of organophosphorus pesticides in the U.S. population. Environ Health Perspect, 112 (2):186-200. [5] Brown, L.M.; Blair, A.; Gibson, R.; Everett, G.D.; Cantor, K.P.; Schuman, L.M.; Burmeister, L.F.; Van Lier, S.F. and Dick, F. (1990). Pesticide exposures and other agricultural risk factors for leukemia among men in Iowa and Minnesota. Cancer Res, 50 (20): 6585-91.

[6] Curl, C.L.; Fenske, R.A. and Elgethun, K. (2003). Organophosphorus pesticide exposure of urban and suburban preschool children with organic and conventional diets. Environ Health Perspe, 111 (3): 377-82.

[7] Ghosh P.K.; Philip L. (2006). Environmental Significance Of Atrazine In Aqueous Systems And Its Removal By Biological Processes: An Overview.Global NEST J, 8(2): 159-178. [8] Gupta, R.C. (2006). Toxicology of Organophosphate \& Carbamate Compounds. Chapter 26, Elsevier Academic Press, Amsterdam, pp. 371-380. [9] Gupta, S.; Stravitz, R.T.; Dent, P. and Hylemon, P.B. (2001) Down-regulation of cholesterol 7alphahydroxylase (CYP7A1) gene expression by bile acids in primary rat hepatocytes is mediated by the c-Jun Nterminal kinase pathway. J Biol Chem, 276 (19): 15816-22. [10] Li, X., Jiang, J., Gu, L., Ali, S., He, J., Li, S. (2008). Diversity of chlorpyrifos-degrading bacteria isolated from chlorpyrifos-contaminated samples. International Biodeterioration and Biodegradation, 62, 331e335 [11] McDaniel K. L.; Moser V. C. (2004). Differential profiles of cholinesterase inhibition and neurobehavioral effects in rats exposed to fenamiphos or profenofos, Neurotoxicol Teratol, 26: 407-415. [12] Routt R. J., Roberts J. R. (1999). Recognition and management of pesticide poisonings.EPA, Washington DC., p.

[13] Sameeh A. M. (2004). Pesticide exposure-Egyptian scene. Toxicol, 198: 91-115. [14] Waddell, B.L.; Zahm, S.H.; Baris, D.; Weisenburger, D.D.; Holmes, F.; Burmeister, L.F.; Cantor, K.P. \& Blair, A.

Agricultural use of organophosphate pesticides and the risk of non-Hodgkin's lymphoma among male farmers 


(United States). $\quad$ Cancer Causes $\quad$ Cont, $12 \quad$ 509-517.
[15] WHO (1986). Environmental Health Criteria 63. Organophosphorous Insecticides : a general introduction. World Health Organization,

Geneva.

[16] Zakov K. (1983). Immunotoxicology of pesticides. In: Kalyanova Tarkowski S, eds. Toxicology of Pesticides Copenhagen. World Health Organization, Geneva; 75-88 (Health Aspects of Chemical Safety, Interim Document No. 